\title{
ABRIENDO NUEVOS CAMPOS EDUCATIVOS Hacia la Educación en Personas Mayores
}

\author{
Dr. Jesús García Mínguez ${ }^{1}$ \\ Universidad de Granada- España \\ Grupo de Investigación HISULA-SHELA \\ jminguez@ugr.es
}

Recepción: 30/05/2008

Evaluación: 24/02/2009

Aceptación: 20/03/2009

Artículo de Reflexión

\section{RESUMEN}

La idea de educación a lo largo de la vida, por cierta y extendida, es un avance que abarca a todos los seres humanos independientemente de la edad. El presente trabajo invita a empujar los impulsos educativos hasta el colectivo de las personas mayores, como medio de capturar la continuidad de una vida cualificada personal y socialmente. Para sostener esta afirmación se adentra en el concepto de educación como derecho reconocido por la ONU en $1948 ;^{2}$ así mismo observa su evolución histórica hasta convertirse en un fenómeno generalmente asumido.

Palabras Clave: Derecho, Educación, Personas Mayores.

\footnotetext{
1 Doctor en Filosofía y CC. de la Educación UNED, Licenciado en Filosofía y Letras Universidad de Granada, actualmente es profesor de la Universidad de Granada - España e Investigador del grupo Historia y Prospectiva de la Universidad Latinoamericana HISULA.

2 Resolución de la Asamblea General de la ONU 217 del 10 de diciembre de 1948.
} 


\title{
OPENING NEW EDUCATIONAL FIELDS: Towards the Education in Adults
}

\author{
Dr. Jesús García Mínguez \\ Universidad de Granada- España \\ HISULA-SHELA Research Group \\ jminguez@ugr.es
}

\begin{abstract}
The idea of education throughout life, certain and extended, is an advance that encompasses everyone independently on his age. This article invites to push the educational impulses to the elderly people, as a way to catch the continuity of qualifiedly personal and social life. To support this statement, the author goes into the concept of education as a right recognized by the ONU in 1948. Likewise he observes its historic evolution to where it becomes a usually assumed phenomenon.
\end{abstract}

KEY WORDS: Right, Education, Elder People

\section{INTRODUCCIÓN}

Con muchos investigadores, abrigamos la convicción de que toda persona y la propia sociedad pueden mejorar continuamente a través de la educación. Lo que se presenta con cierta evidencia es que no bastan los recursos económicos o materiales en sí mismos; en cualquier caso preciso es saberlos gestionar en armonía con unos criterios culturales y educativos. Al respecto hay que hacer hincapié en que la práctica educativa, lejos del sistema de recetario, más bien bajo el concepto de desarrollo riguroso, esto es, programado y participativo, merece nuestra credibilidad.

Desde esta premisa parece adecuado adentrarnos en el campo de la "educación en personas mayores", como un medio de ofrecer al ser entrado en años "el ensayo de nuevos caminos"; el referente emprende la tarea de estructurar otros espacios vitales dirigidos a la mejora de la calidad de vida del adulto mayor. Consecuentemente es un planteamiento de ampliación del espacio educativo.

La trayectoria de la Historia deja sentir que siempre ha habido, latentes o visibles, diferencias y estratificaciones sociales confrontadas: a la memoria acuden la clasificación de los estratos sociales: esclavos y libres, plebeyos y patricios, señores y servidores, 
patronos y obreros, jóvenes y mayores. Félix Santolaria (1997), ${ }^{3}$ ha profundizado en la historia de las respuestas sociales en el contexto español a los problemas de exclusión dando cuenta del recorrido acontecido entre los viejos modelos de atención paternalista hasta los intentos educativos de prevención.

Esta vieja y conflictiva relación humana pareciera desvanecerse en un momento histórico cuando en el siglo XIX surge la cosmovisión de la ilustración. Con la puesta en escena de los sistemas educativos bajo los caracteres de universalidad y obligatoriedad los Estados adquieren la categoría de modernidad y la población asume el rango de ciudadanos de plenos derechos. A partir de la fecha empiezan a relacionarse con estrechos vínculos las ideas de ciudadanía y educación.

El binomio educación -ciudadanía, sociedad-política van a permitir articular tiempos nuevos. Tal como observan algunos historiadores (Viñao y Moreno, 2003; ${ }^{4}$ Vilanou, 2002; ${ }^{5}$ Laspalas (2003), ${ }^{6}$ el giro que tomó la historiografía en el mencionado siglo ha permitido poder ofrecer otras miradas a los sujetos de la historia. Conocer el pasado no es un simple acto de conocimiento o racionalidad, es una manera de recrear los fenómenos pasados para construir la vida del futuro, impidiendo que en nuestra memoria habite el olvido (Nieztche). Efectivamente, la historia puede proclamarse "madre y maestra" por su papel de constructora de futuro, y, sobre todo, siguiendo a Foucault, por ofrecernos herramientas y vías de explicación y orientación.

"La extensión y generalización de la escuela fue entendida como una necesidad primordial en el intento de regeneración de las sociedades". ${ }^{7}$ Prácticamente a lo largo de los años decimonónicos, con algunas anteriores y posteriores excepciones, son instaurados los sistemas educativos de acuerdo con la estructuración que se mantiene hoy día. De ahí que la, red de instituciones escolares "fuera la expresión política a partir de la cual se buscara la edificación de la nueva sociedad y el nuevo ciudadano, según el testimonio de relevantes historiadores como Viñao". ${ }^{8}$ Pérez Ledesma, 2001.) ${ }^{9}$ Bajo la doctrina del potencial transformador pasó la educación a recibir la consideración no sólo de un derecho individual, sino de una condición sine qua non" para el buen funcionamiento del engranaje sociopolítico.

\footnotetext{
3 SANTOLARIA, F. (1997): Marginación y Educación. Historia de la Educación Social en la España Moderna y Contemporánea, Barcelona, Ariel,p.67

4 VIÑAO A. y De Gabriel, N. (Eds.) (1997): La investigación histórico -educativa: tendencias actuales. Barcelona: Paidós, p. 109

5 VILANOU, C. (2002): Jordi Monés i el Seminari d'Historia de 1'Ensengament: quam la historia de la pedagogía esclava historia de l'educatio social. Educari i Historia, 5, 13-59.

6 LAS PALAS, J. (2003): Introducción a la historiografia de la Educación. Pamplona. EUNSA.

7 RUIZ BERRIO, J (1999):“Introducción a la historia de la educación social en España” en Historia der la Educación. Revista interuniversitaria. Vol. VIII, pp 5-11.

8 VIÑAO A. y De Gabriel, N. (Eds.) (1997): La investigación histórico-educativa: tendencias actuales. Barcelona. Paidós

9 PÉREZ LEDESMA. M (2001): "Ese artículo de lujo seriamente odioso", en Archipiélago, pp. $47-15-19$.
} 
No es de extrañar la confianza en las instituciones académicas (escuela, instituto, universidad), ya que los modelos educativos recién estrenados habrían de desempeñar una función básica y estabilizadora en la consolidación de los Estados-Naciones apenas nacidos. ${ }^{10}$ De igual modo, tampoco extrañaba la esperanza depositada en la obligatoriedad: la instrucción básica, así se llamaba, en la escuela aseguraba al conjunto de los ciudadanos los derechos y las competencias que serían capaces de sostener los principios de la democracia y la igualdad. Así pues, el derecho particular de toda persona según Condorcet transciende la individualidad: "la educación, aseguraba el ilustrado francés en la Asamblea Legislativa con términos sonoros, consiste en ofrecer a todos los individuos de la raza humana los medios para hacer frente a sus necesidades, para asegurar su bienestar, para conocer y ejercer sus derechos, para comprender y cumplir sus obligaciones. Su fin es asegurar a todos la posibilidad de perfeccionar sus habilidades de capacitarse para las funciones sociales a las que tiene derecho de ser convocado, de desarrollar por completo los talentos con que la naturaleza lo ha dotado y establecer, por ese medio, una real igualdad entre ciudadanos haciendo de esa manera real la igualdad política que la ley reconoce. Ésta debería ser la nota primordial de cualquier educación nacional $\mathrm{y}$, desde ese punto de vista, la educación es para todo gobierno un deber de justicia" (Discurso sobre educación pronunciado en la Asamblea Legislativa de la Revolución francesa. $)^{11}$

Las reflexiones y las valoraciones que contemplan las palabras de Condorcet sobre la educación afectan profundamente a la visión que mantenían las naciones y los ilustrados librepensadores en 1975: sobre ella descansaba, a su entender, la convivencia social, no menos que la asunción de los derechos cívicos que conducirían a escenarios más ciertos. Es como un proceso de mundialización ("raza humana") de la cultura y la igualdad. No me resisto a contemplar el alcance del optimismo traducido a justicia, prosperidad y felicidad proveniente de la institución educativa y reflejada en las palabras siguientes: "se hace necesario por lo tanto dirigir la enseñanza de manera tal que el perfeccionamiento de las industrias aumente el bienestar de todos los ciudadanos a fin de que un número cada vez mayor de hombres sea capaz de ejercer las funciones que la sociedad requiere. El siempre creciente progreso de la cultura debe ser una fuente inextinguible de ayuda a nuestras necesidades, de remedios para nuestras enfermedades, de medios para la felicidad individual y la prosperidad en general. En resumen, la educación debe cultivar en cada generación las facultades físicas, intelectuales y morales y contribuir al progreso de la raza humana. Este debe ser el objetivo final de toda institución educativa. Por ello la educación es un deber para el gobierno impuesto por el interés común de la sociedad y de toda humanidad". ${ }^{2}$

El armazón lógico del pensamiento de Condorcet tiene una doble dirección: si de una parte la educación entra en el código de los derechos de la ciudadanía, por otro lado, el ejercicio educativo se convierte en requisito para gozar de los beneficios que le

\footnotetext{
10 Op cit., p.19

11 CONDORCET, J. A. (1945): "Informe sobre la organización general de la Instrucción

Pública” en La Escuela Laica. Buenos Aires. Losada, pp. 9-10.

12 Ibídem., p. 15
} 
confiere tal condición. El valor del testimonio condorcetiano no solo ha de medirse por el protagonismo otorgado a la verdad/derecho, cuanto por la capacidad de confianza reservada a la dimensión educativa en la seguridad de otorgar un porvenir "feliz y próspero". Un modo de pensar que evoca principios kantianos.

Sin embargo, los logros no han sido ni tan extensos, ni tan intensos como soñaba la Ilustración y el asambleísta galo. La historia de la educación y la escolarización ha fracasado en doble sentido: porque no consiguió evitar el fracaso y porque al revisar los presupuestos no fue capaz de "controlar las estrategias que actualizan el usufructo de los derechos. ${ }^{13}$ La estrecha relación planteada con optimismo a los inicios, derechoeducación-progreso social, enseguida pareció estar cerca en los discursos y lejos en los cursos. Las desigualdades en los beneficios sociales o materiales no han podido ser borrados por la educación. Hasta hace poco, pongamos por caso, en la sociedad de la robotización o la información o el conocimiento se plantean nuevos y viejos desafíos provenientes de la fragmentación y la inequidad social, lo que tapona la construcción de la plena ciudadanía. ${ }^{14} \mathrm{~A}$ rescatar el ejercicio de los derechos acuden las recientes iniciativas políticas relacionadas con el adulto mayor, así como "reintegrar a los desafiliados", ${ }^{15}$ un segmento poblacional ignorado por los discursos políticos y educativos. La metodología giro en la historia política.

\section{Avanzando Hacia el Derecho de la Educación en el Adulto Mayor}

Hace algunos años con una frase lapidaria pero a nuestro entender acertada, los investigadores García Mínguez y Sánchez García, resumían un pensamiento compartido por la mayoría de los ciudadanos: "urge que la llamada tercera edad deje de ser una edad de tercera". ${ }^{16}$ En efecto, los mayores "no pueden formar un mundo aparte, sólo para ellos, sino que son miembros de la sociedad y han de integrarse y participar en ella". En 1979 la I Asamblea Mundial sobre el Envejecimiento celebrada en Viena y organizada por Naciones Unidas dictaminó el principio de integración en el Plan de Acción Internacional. Justamente éste fue el lema que ha proclamado la celebración del Año Internacional de las Personas Mayores, años más tarde en "Una sociedad para todas las edades" en 1999.

Un ámbito cívico para toda la ciudadanía sin exclusión es aquel en el que caben niños y jóvenes, blancos y negros, adultos y mayores: un espacio humano que valora tanto la prisa como el reposo, la velocidad como la contemplación, la producción y el placer disfrutado, las reminiscencias y la tecnología. Está claro que tal pensamiento es

\footnotetext{
13 RECIO FIGUEIRAS, E. M. (1986): La planificación de los recursos humanos en la empresa. Barcelona. Hispano Europa , p. 245

14 ALVARADO, E. (1998). Retos del Estado de Bienestar en España a finales de los noventa. Madrid. Tecnos.

15 UCAR, J (2006):“El por qué y para qué de la Pedagogía Social” en Planella La Pedagogía Social en la sociedad de la información. Barcelona. UOC.

${ }^{16}$ GARCÍA MÍNGUEZ, Jesús. y SANCHEZ GARCÍA, A. (1998): Un modelo de educación en los mayores: la interactividad. Madrid. Dykinson.
} 
una utopía por el momento; el vector clave de las dinámicas sociales (pensamiento único) es la utilidad: el mercantilismo, la tecnocracia, la productividad, las relaciones productivas, la mitificación de "lo joven", que no de los jóvenes, es el paradigma exclusivo.

Efecto de los valores dominantes, aparecen fronteras que separan algunos segmentos poblacionales sin etiqueta ni privilegios. Existen progresos sociales, pero los avances logrados en los años recientes no impiden que el grupo de personas que "peina canas" conforme una clase distinta y sufra discriminación. Los Servicios Sociales y las Políticas del Estado de Bienestar han experimentado una notable mejoría. "De 1985 a 1997 se ha pasado del $15 \%$ al 25\% sobre el PIB en gasto social". ${ }^{17}$ Con otras cifras, la inversión pública dirigida a las personas mayores (pensiones, sanidad, servicios sociales...) representa un $10 \%$ de la riqueza nacional. Los números podrían contribuir a la tranquilidad y sosiego de la conciencia social ante la obligación que exige ocuparse del largo período de la jubilación. Somos conscientes de que las tasas de cobertura siguen alejadas de las medias necesarias. En parte cumplidos los deberes, hay una atención social que se halla en estado embrionario y que mientras no se promueva generosamente, no puede hablarse de igualdad de oportunidades o derechos compartidos: es la educación en las personas mayores.

"De atrás le viene el pico al garbanzo", decía Sancho. "Desde hace bastantes décadas se recoge la educación como un derecho. La Declaración Universal de los Derechos Humanos proclamada por la Asamblea General de la ONU"18 expresa en su artículo 26 que todos tenemos derecho a la educación, señalando algunas de las características que le son propias: supone el desarrollo personal integral, juicios de valor y el perfeccionamiento como componente ideal.

Art. 26.1. "Toda persona tiene derecho a la educación. La educación debe ser gratuita, al menos en lo concerniente a la instrucción elemental y fundamental. La instrucción elemental será obligatoria. La instrucción técnica y profesional habrá de ser generalizada; el acceso a los estudios superiores será igual para todos, en función de los méritos respectivos".

Art. 26.2. "La educación tendrá por objeto el pleno desarrollo de la personalidad humana y el fortalecimiento del respeto a los derechos humanos y a las libertades fundamentales; favorecerá la compresión, la tolerancia y la amistad entre todas las naciones y todos los grupos étnicos y religiosos, y promoverá el desarrollo de las actividades de las Naciones Unidas para el mantenimiento de la paz".

En el punto primero se concretan aspectos de la educación formal, pero no se limita sólo a este ámbito, sino que entendemos que hace referencia de forma explícita

17 IMSERSO. (2004): Las personas mayores en España. Informe 2004. Datos estadísticos estatales y por Comunidades Autónomas. Vol. I y II. Madrid. Subdirección General de Planificación, Ordenación y Evaluación. Instituto de Migraciones y Servicios Sociales.

18 Resolución de la Asamblea General de la ONU 217 del 10 de diciembre de 1948. 
a otros modos educativos fuera de la escuela ("instrucción técnica, profesional, universitaria). Como toda declaración universal y elaborada con el propósito de ser válida en cualquier momento y lugar, podemos decir que su carácter general deja entrever una concepción de la educación en sentido amplio y global. En esta línea, el punto dos proclama el objeto o finalidad de la educación: "favorecerá la compresión, la tolerancia y la amistad entre todas las naciones y todos los grupos étnicos y religiosos, y promoverá el desarrollo de las actividades de las Naciones Unidas para el mantenimiento de la paz". De su expresión se desprende la extensión a valores fundamentales (paz, amistad, tolerancia), una concepción de la educación como proceso que abarca a toda la persona, durante toda la vida, como ser humano, sin excepción de edad, estado biológico, social,...

La interpretación de lo preceptuado en estos artículos tiene especial valor en el sentido de que, sin pertenecer al orden jurídico, su contenido se convierte en los principios rectores de las políticas de respeto y protección de los ciudadanos, constituyendo un valioso referente en la comunidad internacional. De hecho, las constituciones de muchos países aprobadas con posterioridad a la fecha, tienen como soporte formal la Declaración de la ONU. Por ejemplo, la Constitución Española en su art. 10.2. Expresa: "las normas relativas a los derechos fundamentales y las libertades que la Constitución reconoce se interpretarán de conformidad con la Declaración Universal de los Derechos Humanos y los tratados y acuerdos internacionales sobre las mismas materias ratificadas por España”.

Para empezar recordemos que la actividad educativa en nuestro país es un registro de principio: "Todos los españoles tienen derecho a la educación" (Art. 27). A su vez, "la dignidad de la persona, los derechos inviolables... el libre desarrollo de la personalidad" consolida unos criterios que no distinguen entre niños, adultos o jubilados, negros o blancos, creyentes o agnósticos. El artículo 14: "los españoles son iguales ante la ley, sin que pueda prevalecer discriminación alguna por razón de nacimiento, raza, sexo, religión, opinión o cualquier otra condición o circunstancia personal o social" reafirma esta lectura subliminar a través de la expresión "todos" que expone el punto primero del anterior artículo 27.

Está claro el derecho que se nos reconoce, pues en la proyección de la vida del ciudadano español, no cabe elección de momento o espacios para la educación. "La igualdad humana sólo es posible en la amplia gama del parámetro vital marcada por el recorrido que va desde que nace hasta que muere."19 La Constitución no admite excepciones tanto más, cuanto "todos somos iguales ante la ley".

El punto segundo del artículo 27 especifica que "la educación tendrá por objeto el pleno desarrollo de la personalidad humana en el respeto a los principios democráticos de convivencia y a los derechos y libertades fundamentales" lo que indica que la educación es algo más que aprendizaje, formación y/o transmisión de conocimientos,

19 GARCÍA MÍNGUEZ, Jesús. (2004): La educación en personas mayores: ensayo de nuevos caminos. Madrid. Narcea, p. 49.

Rhela. Vol. 12. Año 2009, pp. 129 - 151 
pues el "pleno desarrollo de la personalidad humana" es defendida "por la educación antes que por la elección de un modelo de aprendizaje como prefiere Peter Jarvis". ${ }^{20}$ En su fin último se preocupa por la evolución y desarrollo integral de la persona, la cual, va adquiriendo un conjunto de valores, conocimientos e ideas que tienen como objetivo prepararla ante la vida con posibilidades de libertad e integración social. El derecho a la educación es un "ámbito tan extenso, tan dinámico, tan cambiante que, a menudo, podemos tener dificultades para concretar exactamente qué es lo que está referenciado con dicho apelativo." ${ }^{21}$ Parece claro que lo educativo por derecho se concretaría en todas aquellas situaciones y comportamientos individuales y colectivos que posibilitan una vida más digna, más justa, más tolerante.

"Tal y como continúa Jesús García Mínguez"22 "podríamos asegurar que casi ninguna Constitución de países modernizados ha olvidado incluir en su catálogo de obligaciones, el referido a la educación", tanto por su importancia como por su trascendencia, ya que de una parte defiende la dignidad humana como quizás ningún otro tratado, y al tiempo aparece como la condición de realización de otros derechos fundamentales. Hay un entrelazado de derechos sujetos al disfrute educativo, de manera que la pérdida de éste hace inviable el disfrute de otros. Siguiendo a María Isolina Dabove $^{23}$ el derecho a la educación (art.27) se relaciona asimismo con el derecho de acceso a la cultura (art.44), con el derecho a la libertad de expresión (art.20), con el derecho a la participación en los asuntos públicos, directamente o por medio de representantes (art.23); con el derecho de peticionar ante las autoridad (art.29), con el derecho de reunión (art.21), de asociación (art.22) y de fundación (art.34).Y podríamos seguir citando otros como es el derecho a exigir la conservación de patrimonio histórico, cultural y artístico del país (art. 46).

El problema lo encontramos cuando chocamos de frente con la realidad de países que a pesar de disponer de la titularidad del derecho, no tienen posibilidad de ejercerlo. En el contexto español, esto vendría a cobrar sentido con las personas mayores, las cuales no gozan plenamente de él, a pesar de que la Carta Magna, en su art. 9.2. Exprese que respecto a la ley: "corresponde a los poderes públicos promover las condiciones para que la libertad y la igualdad del individuo y de los grupos en que se integran sean reales y efectivas; remover los obstáculos que impidan o dificulten su plenitud y faciliten la participación de todos los ciudadanos en la vida política, económica, cultura y social”. Entendemos que este incumplimiento puede tener su explicación en dos causas:

a) la percepción de las personas mayores como ciudadanos "retirados" e improductivos, de tercera categoría y

b) la concepción de la educación ceñida al ámbito formal y para un intervalo de edad concreto.

\footnotetext{
20 Ibídem., p.46.

${ }^{21}$ UCAR, J. (2006): "El por qué y para qué de la Pedagogía Social “, en Planella La Pedagogía

Social en la sociedad de la información, Barcelona, UOC, p.236

${ }^{22}$ Ibídem., p.46.

23 DABOVE, M. I. (2002): Los derechos de los ancianos. Buenos Aires. Ciudad Argentina.
} 
Sin embargo, no puede justificarse que el derecho a la educación no se ejecute y se impida el disfrute de este tributo a no importa qué ciudadano. Queda constatado que para la Constitución, la participación en el ejercicio educativo es un derecho que corresponde a la totalidad de los españoles sin prejuicio de edad o estado biológico. Existe pues, un mandato constitucional inequívoco que viene a reconocer el interés de la educación a cualquier nivel y estructura humana.

Estamos llegando al momento que nos interesa: digamos que el imperativo constitucional de la educación extiende su ampro tanto al joven como al mayor, aunque seguimos pensando que éste colectivo aún "está fuera de juego" o para no ser injustos digamos que empieza a gozar de usufructo de su derecho. El concepto de Estado de Bienestar y las políticas sociales proveen a las diferencias de la ciudadanía, en particular el ámbito del adulto mayor. Tal compromiso del Estado de Bienestar con la mejora de vida del colectivo marginal de los jubilados se traduce en atención a pensiones, salud, voluntariado, asociacionismo y, como no podía ser menos, la educación. Más acá o más allá de consideraciones marginales, "no nos adentramos en la polémica de si los efectos que produjo y los que puedan seguir apareciendo, la clarificación sobre si realmente ha llegado a existir en nuestro país algo parecido a un Estado de Bienestar, si llegó a cuajar o si lo hizo con efímera vida." ${ }^{24}$ Importa resaltar que los esfuerzos de la sociedad a favor del segmento más alto de la pirámide humana son los más distinguidos de toda nuestra historia.

"Se inicia de esta manera una corriente política que devendrá hegemónica y que va a ir fijando su radio de acción y su pensamiento más allá de la atención asistencial, en ocasiones precisa, de los sujetos carenciales". ${ }^{25}$ "Con el concurso de una nueva imagen del mayor," 26 la aparición de "una clase social" que empieza a despertar, ${ }^{27}$ y una sensibilidad en las políticas sociales empezamos a reconocer no sólo el derecho a la educación, sino a comprender en qué consisten los perfiles educativos en el adulto mayor.

\section{Desarrollando la Constitución. La educación como Derecho Real}

Por primera vez que sepamos, la legislación española se ocupa directamente de la educación en las personas mayores: la "Ley de atención y protección a las personas mayores" de la Junta de Andalucía no desaprovecha la ocasión para presentar un nuevo planteamiento, una nueva prestación de los servicios sociales: en el Título VII otorga una dedicatoria a la Educación y Formación. La dinamización del "derecho a la educación en las personas mayores se promoverá mediante:

\footnotetext{
24 SÁEZ, J. Y GARCÍA MOLINA, J. (2006): Pedagogía Social. Pensar la Educación Social como profesión. Madrid. Alianza Editorial, p. 196.

25 QUINTANA CABANAS, J. M. (1999): Textos clásicos de Pedagogía Social. Valencia: Nau Llibres.

${ }^{26}$ GARCÍA MÍNGUEZ, J. (Coord.) (2005): Programas de Educación Intergeneracional. Acciones Estratégicas. Madrid. Dykinson.

${ }^{27}$ SÁEZ CARRERAS, J. (2005): "La socialización de las profesiones. La construcción de la identidad profesional del educador social", en GARCIA MÍNGUEZ, Jesús. (Coord.): La Educación Social: discurso, práctica y profesión. Madrid. Dykinson, pp.99-126.
} 
1. la potenciación de la educación de adultos.

2. la organización, por parte de las Universidades, de cursos y otras actividades formativas.

3. el fomento de talleres ocupacionales específicos.

4. la elaboración de programas con diferentes niveles educativos que propicien el encuentro y entendimiento intergeneracional".

El adulto mayor no puede renunciar alegremente a la conquista de un derecho, pero sobre todo la posibilidad de disponer de un tiempo para aprender, para fijar o cambiar valores, para seguir completando la realización de nuevos proyectos de vida. Ahora estamos de acuerdo en que, cubiertas las necesidades primarias (pensión y salud) el mayor y/o cualquier ciudadano tiene la oportunidad de cumplir el sueño del griego, el cultivo del logos mediante la educación. Ahora es más fácil sentirse interpelado por el dicho popular: "llenar los años de vida".

Quizás en el gran colectivo de los mayores el culto del espíritu esté más retrasado que la reivindicación del derecho; pero consideramos oportuno contribuir a esclarecer y actualizar la racionalidad adormecida. Con la sabiduría y experiencia de la biografía del mayor se están abriendo otras posibilidades para la propia persona y la sociedad que no podemos ignorar. No se intenta emular a Platón o a Nieztche, pero si la sabiduría antigua todavía sirve para algo, recordemos con ella que mientras hay vida, habrá esperanza. La esperanza de un nuevo perfil del mayor cultivando la mente y el espíritu.

"Harina de otro costal es el planteamiento del concepto de educación en las personas maduras. Lo que parece claro es que la curiosidad y deseo de aprender no tiene límites", ${ }^{28}$ el sentir y descubrir ni se retrasa, ni desaparece con los años."Muriendo y aprendiendo", asegura la filosofía popular. Educar tiene sentido; el qué y el cómo están por ser reconocidos y delimitados. El primer paso del camino a recorrer es el qué.

\section{Educación Permanente Educación a lo Largo de la Vida}

La cuestión de la educación en los adultos mayores, los rasgos y las notas que la configuran exige una reflexión que permita caracterizar el tipo de apuesta que la literatura específica viene haciendo, así como el espíritu que la anima. Diversos autores en nuestro país (Sánchez, 1998; Sáez, 1998, 2002, 2004, 2005; Víctor, 1996; Escarbajal, 2004; García Mínguez, 1998, 2004, 2005; Montero, 2005) han intentado una primera caracterización que nos adentre en este complejo concepto. Merece la pena, es una obligación tratar de explicar qué entendemos por educación en nuestra tesis y qué modelo dirige el trabajo. Tomando como referenciales los estilos conocidos, en ocasiones confundidos vamos a asociar la educación en personas mayores, por el carácter extensivo que acarrea al concepto de Educación Permanente y posteriormente a la asignación de educación a lo largo de la vida.

${ }^{28}$ GARCÍA MÍNGUEZ, Jesús y SANCHEZ GARCÍA, A. (1998): Un modelo de educación

en los mayores: la interactividad. Madrid. Dykinson. 
Muy recientemente, década de los 70, la transformación y el sentido realista de la educación se han convertido en un proyecto sin fronteras en la historia del individuo. "Si la educación es transformación de la realidad... tendremos que la Pedagogía es la ciencia de transformar sociedades. Antes llamamos a esto política; he aquí pues, que la política se ha hecho para nosotros pedagogía social y el problema actual es un problema pedagógico. Buena parte de la influencia que Ortega atribuye a la educación tiene su asentamiento en una nueva y extensiva concepción, allá por los años 40 y que recibió el título de Educación Permanente.

"El concepto de Educación Permanente, asegura Edgar Faure, se extiende a todos los aspectos del hecho educativo; engloba a todo y el todo es mayor que la suma de las partes. En la educación no se puede identificar una parte distinta del resto que no sea permanente. "Dicho de otro modo: la Educación Permanente no es sólo un sistema, ni un sector educativo, sino un principio en el cual se fundamenta la organización global de un sistema, por tanto, la elaboración de cada una de las partes". ${ }^{29}$

El Presidente de la Comisión Internacional para el desarrollo de la Educación entiende que ésta no ha de centrarse en períodos concretos del devenir historiográfico, ni puede ser concebida de forma segmentada, sino como un sistema, un ejercicio en el tiempo equivalente a la duración de la vida. Cualquier país, que se precie de "pensamiento progresista" habla y planifica la educación de las personas adultas igual que la formación inicial de los escolares. Es la Conferencia de Nairobi, portavoz del espíritu de un organismo internacional, la UNESCO, en $1976,{ }^{30}$ quien daba total validez transnacional a la idea de la educación como programa total para la vida de los individuos:

"La expresión Educación Permanente designa un proyecto global encaminado tanto a reestructurar el sistema educativo existente, como a desarrollar todas las posibilidades de formación fuera del sistema educativo:

- en este Proyecto, el hombre es el agente de su propia educación por medio de la interacción permanente de sus conductas y reflexión;

- la educación permanente, lejos de limitarse al período de escolaridad, debe abarcar todas las dimensiones de la vida, todas las ramas del saber y todos los conocimientos prácticos que pueden adquirirse por cualquier medio a fin de contribuir al desarrollo de la personalidad de la mejor forma posible;

- la intervención educativa que se extiende a lo largo de la vida (niño, joven, adulto), ha de considerarse como un todo, cualquiera que sea su forma".

Tras la lectura de este documento no se puede buscar excusa alguna para insistir sobre una orientación que no alcanzara otras etapas más allá de los niveles básicos, medio y superior. De acuerdo con las declaraciones políticas la formación es permanente en todos los sentidos:

29 FAURE, E. y otros (1972): Aprender a ser. La educación del futuro. Madrid. Alianza. ${ }^{30}$ UNESCO. (1976): Recomendación relativa al desarrollo de la educación de adultos aprobada por la Conferencia General en su decimonovena reuniónNairobi, 26 de noviembre de 1976. 
- bajo la dimensión temporal ("sin interrupción en la vida),

- desde la perspectiva de los contenidos ("todas las ramas del saber"),

- la óptica del método ("por medio de la interacción conducta - reflexión") y

- los fines a conseguir ("desarrollo de la personalidad en la mejor forma posible").

El manifiesto considera asunto clave el concepto y la realidad del proceso educativo otorgándole el nombre de "proyecto global", sin tregua, sin sobresaltos, sin sectorizaciones. La propia Constitución Española en su famoso artículo 50 afirma con rotundidad: "los poderes públicos garantizan, mediante pensiones adecuadas y periódicamente actualizadas, la suficiencia económica a los ciudadanos de la tercera edad. Así mismo, y con independencia de las obligaciones familiares, promoverán su bienestar mediante un sistema de servicios sociales que atenderán sus problemas específicos de salud, vivienda, cultura y ocio" (Art. 50). La educación, al contrario que el trabajador, no tiene jubilación; es la gran ocupación a lo largo de la existencia cuyo derecho corresponde a partes iguales al ciudadano y sociedad a través de los "poderes públicos".

El documento va más allá, para no dejar espacio a la duda o a interpretaciones equívocas. De la afirmación general sobre la educación de adultos desciende a operativizar la intervención con la Tercera Edad: "en cuanto a las personas de edad las actividades de educación de adultos deberían ir encaminadas, en particular, a garantizar a todos:

- una mejor comprensión de los problemas contemporáneos y de las generaciones jóvenes,

- a los mayores, las posibilidades que les ayudan a aprender a aprovechar el tiempo libre, a vivir en buena salud y a encontrar un mejor sentido a la vida,

- a quienes se disponen a abandonar la vida activa, una iniciación a los problemas que se plantean a los jubilados y los medios de hacer frente a esos problemas,

- a quienes han salido ya de la vida activa, la conservación de sus facultades físicas e intelectuales y el mantenimiento de su participación en la vida colectiva, así como el acceso a unos campos de conocimiento o a unos tipos de actividad que no estaban a su alcance durante su vida laboral."

Existen, como puede observarse, un buen número de recomendaciones para todos los ciudadanos y para el colectivo de los mayores en particular, insistiendo especialmente en la conservación de sus "facultades intelectuales". Se da por sentada la capacidad de aprender y por superada esa especie de consenso implícito que reduce a los mayores a "un aparte" sin "acceso a los campos de conocimiento". En contra de la filosofia segregacionista faltan leyes, pero sobre todo se echa de menos una atención educativa permanente.

En sus inicios la Educación Permanente, aunque nacida al abrigo del desarrollismo, no es un discurso oportunista, al estilo del discurso retórico político, ni el servidor de sospechosos intereses: dos soportes, filosófico uno, sociológico el otro, ponían su granito de arena a la ilusión de un programa guardián de la globalidad existencial. Una de las grandes y apasionantes contribuciones de la filosofía heideggeriana viene dada por la 
razón ontológica del humano: el hombre es "un proyecto inacabado"; la existencia humana surge con la esperanza de un desarrollo continuo donde el tiempo juega a la sorpresa y la imprevisibilidad; ${ }^{31}$ el destino del hombre es hacerse sin tregua hasta el final de su existencia. Somos abnegados constructores de nosotros mismos, afortunados condenados a las galeras de la ininterrumpida construcción.

En esta faena de personalización estábamos. Pero los tiempos cambian arrastrando ideas y verdades: Efecto del desarrollismo en los años 80 la Educación Permanente rinde tributo a sociedad del pensamiento único: el hombre tiene que vivir como ser cultural de su tiempo, es decir, de los productos de su acción previsora, planificada y mancomunada que le permita procurarse instrumentos y técnicas para resolver su propia vida. ${ }^{32}$ "El apadrinamiento del compromiso social pierde perspectiva cultural". ${ }^{33}$ Cada momento de la existencia requiere un "tempus" para subsistir y para promover el hábitat propio. Conocida la evolución y los cambios sociales, lo que se demanda a la educación son garantías de "actualización productiva" en el trabajador. La función de la Educación Permanente pasa a ser definida y controlada desde los contextos contaminados ideológicamente por el positivismo.

La suya es un función prestataria, generada principalmente por la sumisión al beneficio económico o los elementos finalistas; pongamos como recordatorio dos acciones clásicas con metas definidas y específicas: la utilización de la Educación Permanente en los escenarios laborales (bancos, empresas, circuitos informáticos...) o los cursillos de formación para mandos intermedios, maestros que piden "técnicas "para trabajar en la escuela. Tales expresiones no dejan de ser más que subproductos de una educación instrumental antes que de una educación expresiva. Un tal modelo educativo viene a ocupar los espacios y moldes de una concepción fundamentalmente "tecnocrática," ${ }^{34}$ a fin de allanar la eficiencia del trabajador.

"Formarse...ampliar capacidades... desarrollo personal y profesional", son términos que evocan y ponen el acento en la instrumentalidad. Asimilados en algunos textos los conceptos educación a lo largo de la vida y Educación Permanente parecen haberse refugiado en unas prácticas asociadas a la actualización profesional. Como discurso primordialmente metodológico, los programas de prácticas educativas permanentes derivan hacia el encuentro con las "microtecnologías" que denunciaba Foucault: decididamente estamos ante una organización del saber para la captación de resultados.

Sin embargo el camino "analítico y empírico," ${ }^{35}$ de la educación a lo largo de la vida salta por encima de la lógica positivista, cuentan de uno de los mejores pensadores

\footnotetext{
31 SÁEZ CARRERAS, J. (2004): La profesionalización de los educadores sociales: en busca de la competencia educativa cualificadora. Madrid. Dykinson.

32 ESCARBAJAL DE HARO, A. (2004): Personas mayores, educación y emancipación: la importancia del trabajo cualitativo. Madrid. Dykinson.

33 SÁEZ CARRERAS, J. Op., cit. p. 30.

${ }^{34}$ SÁEZ CARRERAS, J. Op., cit. p. 35.

${ }^{35}$ INKELES. (1968): ¿Qué es la sociología? Introducción a la ciencia y a la profesión. México. Uthea.
} 
clásicos e incluso de todos los tiempos como Sócrates, que mientras le preparaban la cicuta con la que iba a ser eliminado por corruptor de la juventud ateniense, estaba aprendiendo un aria para flauta. Preguntado, ¿"de qué te va a servir"? El viejo filósofo contestó, "para saberla antes de morir". De muy lejos se viene diciendo, que "el saber no ocupa lugar" o que "el aprendizaje no tiene edad". Quienes así piensan se encuentran en la convicción según la cual "el tiempo es oro" lo que aplicado a la biografía de cada persona se traduce en un posible desarrollo continuado. No obstante, otros, muy al contrario, piensan que no merece la pena ningún esfuerzo o derroche de energías cuando llevados por un principio inspirado en el realismo y practicismo, asegura con resolución que no hay espacio ni tiempo para el hombre actual. ${ }^{36}$ A no dudar que el viejo Sócrates se encontraba entre los primeros.

La educación expresiva a lo largo de la vida, principal argumento validable de la Educación en Adultos Mayores, encuentra su naturaleza en el espacio del comportamiento emocional/racional en primera instancia. De alguna manera, la expresión educativa se presenta para definir y desarrollar la consciencia de las propias capacidades sean racionales sean afectivas. Estamos planteando un modelo educativo que incorpora los avances de los nuevos conocimientos y tecnologías junto al esfuerzo por incorporar el patrimonio individual o colectivo del mundo emotivo

Es así como la herencia de las personas viene a ser considerada como "el capital personal, social y cultural." ${ }^{37} \mathrm{El}$ referente del propio conocimiento y los cambios de la persona hay que entenderlos en el marco de la expresividad emotiva que viene a convertirse en el territorio de la alfabetización de la conciencia. Los nuevos avances y retrocesos en el proceso de integración del mayor se fraguan en las dimensiones de la "inteligencia emocional" de la que dependen importantes implicaciones en las relaciones sociales, junto a otros aspectos de la vida. ${ }^{38}$ El punto de partida no es un planteamiento disyuntivo: la razón positivista o los sentimientos, el modelo de la eficacia o el modelo de la experiencia, las competencias técnicas o las competencias expresivas. Las últimas investigaciones han aportado pruebas convincentes de la inseparabilidad esencial de las emociones y el razonamiento.

En la década de los noventa encontramos en el Informe Delors ${ }^{39}$ por primera vez la acertada y expresiva elocución, "educación a lo largo de toda la vida" como réplica a los desvíos de la Educación Permanente. En verdad el concepto de Educación Permanente había sido absorbido por el pensamiento eficientista. De hecho, en muchos documentos aparece el proceso educativo permanente adscrito a la idea de aprendizaje. El propio, Delors lo interpreta como referencia no a un periodo particular de la existencia,

\footnotetext{
${ }^{36}$ NÚÑEZ, V. (1999): Pedagogía Social: cartas para navegar en el nuevo milenio. Buenos

Aires. Santillana, pp. 83.

${ }^{37}$ GARCÍA MÍNGUEZ, Jesús. (Coord.) (2005): Programas de Educación Intergeneracional.

Acciones Estratégicas. Madrid. Dykinson.

38 GOLEMAN, D (2001): La inteligencia encinal. Barcelona. Kairós.

39 DELORS, J. (Coord.) (1996): La educación encierra un tesoro. Informe de la UNESCO

de la Comisión Internacional sobre educación para el siglo XXI. Madrid. Santillana.
} 
sino como el ejercicio de aprendizaje que se extiende a toda la vida, donde cada tipo de conocimiento invade a la persona y la enriquece. Como construcción de un sistema de agencias la actividad de permanente educación parece directamente relacionada con aprender para "invadir la persona (con conocimientos) y enriquecer, término que llama a la paradoja.

Para nosotros junto a otros autores; ${ }^{40}$ Pérez Serrano; ${ }^{41}$ Colectivo Situaciones y Universidad Trashumante ${ }^{42}$ el contenido de "educación a lo largo de la vida tiene un sentido más fenomenológico y menos positivista. Educar fenomenológicamente responde a una función de construcción y transformación, es decir, representa la ayuda para entrar en un proyecto de vida. Las pautas educativas hacen hincapié en el valor de la vida, expresión clave del ser y estar del hombre según el entendimiento existencialista por ejemplo de Ortega. El "ser y estar", interpretados en su sentido estructural y biográfico, no sólo en el sentido espacial, llevan al concepto de "instalación", que es la manera como el hombre "se encuentra" en la vida, haciendo "ya" algo, y siendo "ya" alguien. ${ }^{43}$

En este sentido, la educación expresiva a lo largo de la vida no deja de ser un espacio de contagio de ilusiones y deseos, de re-creación de proyectos, de re-situación ante lo que nos rodea, de adquisición de nuevas competencias frente a otros horizontes. Cada sujeto, cada persona mayor tiene su currículo y lo que sea capaz de ser o hacer será efecto de una reflexión sobre sus fortalezas y debilidades trabajando con otros, entre otros. Porque finalmente se trata de poner en escena una herencia significativa de años, un crear e innovar conocimientos sustraídos de la enciclopedia de la vida. Es un desplazamiento más allá del yo mismo, redescubriendo lo que sabe y ha vivido en biografía conducida hacia los otros.

A partir de la fenomenología orteguiana, finalmente Marías es un aplicado discípulo, los verbos "ser y estar" refieren la estructura empírica y existencial del hombre. "A todos nos interesa vivir en un ambiente lo más inteligente posible, porque va a ofrecernos mayor oportunidad de ser felices y llevar una convivencia más digna." ${ }^{44}$ Es una apuesta a favor del "estar" o si se prefiere una opción por el rostro más humano y social del fenómeno educativo.

Lo que caracteriza al mundo de la educación a lo largo de la vida tal vez sea un efecto de peculiar resonancia ante la realidad vital que vale tanto para un pensamiento como para una obra externa, con frecuencia "desagregados;", 45 es una ubicación en una

\footnotetext{
40 NÚÑEZ, V. (1999): Pedagogía Social: cartas para navegar en el nuevo milenio. Buenos Aires. Santillana

${ }^{41}$ PÉREZ SERRANO, G. (2003): Pedagogía Social. Educación Social. Madrid. Nancea.

42 COLECTIVO SITUACIONES (2004): Algo más sobre la militancia de investigación. Notas al pie sobre procedimientos o (in)decisiones. En VV.AA. Nociones comunes, experiencia y ensayos entre investigación y militancia. Madrid. Traficantes de Sueños, pp. 93-110

43 MARÍAS, J. (1993): La educación sentimental. Madrid. Alianza, p. 21.

${ }^{44}$ MARINA, J. A. (2004a): Anatomía del miedo: un tratado sobre la valentía. Barcelona. Anagrama.

${ }^{45}$ NÚÑEZ, V. Op., cit. p. 90.
} 
continuidad vital donde la atracción del cambio personal o social puede "armar una estructura... de socialización de capacidades." ${ }^{46}$ Toda la obra de Platón, Rafael o Dickens interesan por su belleza y también porque "son productos de la vida de las sociedades diferenciadas y se extraen de la praxis vital." ${ }^{47}$ La educación a lo largo de la vida construye al artista en sentido simbólico, es decir, aquel sujeto para quien el ejercicio educativo no puede serle indiferente y que, más bien, sirve para descubrirse a sí mismo y su entorno. Sabido es que el conocimiento cuenta como una herencia que da una gran satisfacción aunque mayor gratificación produce el hallazgo de unas capacidades propias que acaban de desvelarse.

Llegados a este punto no puedo seguir aplazando el tema decisivo de cómo descubrir los "acantilados" 48 de la educación a lo largo de la vida y encontrar la disponibilidad de un nuevo tiempo para una nueva persona. El problema va unido a dos preguntas elementales: ¿qué instrumento es capaz de permitirnos saber más de lo que sabemos de nosotros mismos? y ¿cómo podemos hallar la fórmula que permita acercarnos, no a lo que somos, sino a lo que podemos ser? Por una extraversión de valores, la primera cuestión deja constancia del ser en términos aristotélicos ("el ser es lo que es"), mencionados arriba, mientras que la segunda testimonia el poder ser en expresión "vigostkyana"; la "zona de desarrollo próximo" es la preocupación del investigador ruso Vigostky. Él definía "la zona de desarrollo próximo como la distancia entre el nivel del desarrollo real... y el nivel más elevado de desarrollo potencial determinado por la resolución de problemas." ${ }^{49}$

La escuela y la educación deberían servir para hacer entender a cada uno de nosotros que ninguna empresa es definitiva y que la experiencia de la posibilidad es una operación matemática y humana. Ahora bien, téngase presente algo importante: la sorpresa de los posibles en el ámbito antropológico vale tanto para el joven como para el mayor, a expensas de seguir la indagación "del temple de la vida". En la memoria biográfica del hombre se esconden los pliegues de la curiosidad que reservan imprevisibles experiencias de orden creativo y que ponen a prueba el potencial de la "zona de desarrollo próximo".

No hay edad para participar en las aventuras del espíritu, sean bellas invenciones, sean "ópera prima." ${ }^{50}$ Es el momento de referirnos a las personas entrantes en años. Claro está, el mundo de los mayores también es capaz de engendrar artefactos brillantes porque el vasto territorio de la superación desde la educación expresiva no repara en discriminaciones de ciclos vitales. La teoría de Vigostky no dimensiona la diferencia entre lo que fue y lo que es la persona sino entre lo que es y la fortuna que puede

\footnotetext{
46 PLANELLA, J. (2006): Los hijos de Zotikos: una antropología de la Educación Social. Valencia, Nau Llibres, p .79

47 NÚÑEZ, V. (2002): La educación en tiempos de incertidumbre: la apuesta de la Pedagogía Social. Barcelona. Gedisa, p. 45

48 GARCÍA MOLINA, J. (Coord.) (2003): De nuevo, la Educación Social. Madrid. Dykinson.

49 VYGOTSKII, (1989): El desarrollo de los procesos psicológicos superiores, Barcelona. Crítica.

${ }^{50}$ GARCÍA MÍNGUEZ, Jesús. (2004): La educación en personas mayores: ensayo de nuevos caminos. Madrid. Narcea.
} 
adquirir, independientemente de los años. Hay que repetirlo, el punto de mira de la educación a lo largo de la vida no es el pasado sino el porvenir. El mérito está en saber articular las sorpresas del futuro toda vez que ninguna persona es capaz de conocerlas ni de controlarlas. A descubrir el vasto territorio de lo no consciente viene este modelo de educación convertida en fórmula para transformar el viejo slogan de quiénes somos y dónde vamos por aquel otro de quiénes somos y a dónde podemos llegar. Es la educación de los posibles; es "el reconocimiento siempre tardío de una realidad que desde la década de los noventa venían reclamando los estudiosos de la Pedagogía Social.

En las mismas coordenadas del trabajo sobre el propio edificio "la educación en personas mayores consiste en el ensayo de nuevos caminos como prolongación de la biografia personal y social." ${ }^{51}$

"El sujeto del ensayo educativo es el propio mayor que desde su personalidad otea otros proyectos de vida. Históricamente la educación ha supuesto una modificación del niño o el adulto" 52 : la escuela, por ejemplo, ha marcado unas normas, unos valores, unos conocimientos a los que el escolar debía ajustarse. Sea por prescripción de Boletín Oficial, sea por prescripción disciplinar del maestro, el educando siempre fue acompañado por el papel de receptor, mientras que raras veces asumió las funciones de actor. Sin embargo, en el proceso educativo de las personas mayores hemos de acentuar una inversión de funciones: lo normal es que el adulto mayor ocupe la cabina de mandos previendo que raras veces devenga en pasajero llevado por otros. Con todo, seamos realistas, éste no es más que el ideal hacia el que tiende la ciencia de la Pedagogía Social a cuya comprensión nos hemos aplicado en páginas anteriores, asociando al ejecutor, esto es el educador social a la nueva situación del adulto mayor.

Quiero remarcar que la proyección de nuevos caminos entronca con la teorización de Vigostky ${ }^{53}$ : buscar cada quien los talentos ocultos, las expresiones y escenarios diferentes, es la condición fundamental de la teoría de "la zona de desarrollo próximo" asociado al proceso educativo sin límites de edad. Esta intención creadora supone un desafío en el escenario del colectivo de mayores. Ya no se trata de matar el tiempo con un entretenimiento, el juego a la petanca, el taller de pintura o de baile. Más bien se trata de descubrir nuevos interrogantes y dejar paso a un espíritu emprendedor de "nuevos proyectos" ${ }^{\prime 4}$ para contrarrestar la vida sedentaria. Desde el punto de vista psicológico se trata de una secreta ofensiva contra una futurible artrosis mental. Así pues, el reto conduce al descubrimiento de los valores adormecidos en el "sexagenario y más", reconocidos y asociados a la creatividad y el compromiso social.

La experiencia es inseparable de la renovación. El mayor entre otras cosas, ha construido el edificio de su personalidad desde la vida y desde esa plataforma está en el

51 Ibídem., p 46.

52 PETRUS, T. (1998): Pedagogía Social. Barcelona. Ariel.

53 VYGOTSKII. (1989): El desarrollo de los procesos psicológicos superiores. Barcelona. Crítica.

54 GARCÍA MÍNGUEZ, Jesús. Op. cit. p. 45. 
camino de reconducirla si preciso fuere. La historia y experiencias del pasado son campos magnéticos que proyectan el futuro en aquéllos que tienen la suerte de escuchar la llamada sorpresiva de la conciencia creadora.

Más allá de estas reflexiones hago constar un riesgo: muchas personas padecen la tentación de catalogar a los semejantes con frases hechas: "a la vejez viruelas", "yo ya para qué", "es un viejo de setenta años": así se clasifica a cada uno de los ciudadanos. Repetidas veces se oyen juicios de esta guisa falazmente descalificadores, aplicados sobre todo al segmento poblacional de los jubilados. Al "retirado" se endosa el "sanbenito" de ser inútil, improductivo, parásito, cascarrabias, achacoso, viejo, gruñón... basta recorrer, pongamos por caso, al imaginario popular del refranero. ${ }^{55}$ Pero nada más lejos de la realidad: la persona mayor, igual que el joven o el niño emplazados otros intervalos erarios más aceptados, posee la oportunidad de demostrar que vale y sirve para algo, a condición de que trabaje su corazón y lance al exterior las dotes racionales o imaginativas con el ayuntamiento de un seguimiento educativo existencial. Los resultados presentes en la historia (Cicerón, Cervantes, Miguel Ángel, Goete...) son argumentos demostrativos de especiales capitales a altas edades y que con la maestría de sus obras han mostrado ante sus semejante la falsedad del patético etiquetaje social de los prejuicios.

\section{CONCLUSIONES}

Digamos como resumen que la educación a lo largo de la vida ha de plantearse como proyecto eminentemente activo, participativo y constructivo, a través del cual se disciplinan expectativas, optimizan capacidades, se fomenta la libertad y autonomía (Escarbajal, A., 1994, ${ }^{56}$ 2003; ${ }^{57}$ Muñoz, I., 2003; $; 8$ Bedmar, M y otros, 2004; $;{ }^{59}$ García Mínguez, J., 2004, ${ }^{60} 2005^{61}$ y Montero, I., 200562).

\footnotetext{
55 GARCIA MINGUEZ, Jésus. et Alii. (2003): El refranero, ¿espejo y reflejo de las personas mayores? Madrid. Dykinson.

56 ESCARBAJAL DE HARO, A. (1994): La marea gris. En J. Sáez (Coord.), La educación de adultos ¿una nueva profesión? Valencia. Nau Llibres, pp. 209-228.

57 ESCARBAJAL DE HARO, A. (2003): "Personas mayores, educación y aprendizaje. en J. SÁEZ, (Coord.), Educación y aprendizaje en personas mayores). Madrid. Dykinson. pp.158181.

58 MUÑOZ GALIANO, I. (2003):“Una apuesta para el futuro: la educación en personas mayores”, en J. A. Lorenzo Vicente (Dir.), Políticas sociales, educativas y financiación de la formación universitaria de personas mayores y su proyección social (pp. 165-173). Madrid: IMSERSO

59 BEDMAR, M. y otros. (2004): Gerontagogía. Educación en personas mayores. Granada. Grupo Editorial Universitario

60 GARCÍA MÍNGUEZ, J. (2004): La educación en personas mayores: ensayo de nuevos caminos. Op., cit.

${ }^{61}$ GARCÍA MÍNGUEZ, Jesús, (Coord.) (2005): Programas de Educación Intergeneracional. Acciones Estratégicas. Op., cit.

${ }^{62}$ MONTERO GARCÍA, I. (2005): El interés de las personas mayores por la educación: qué educación. Estudio de campo. Tesis Doctoral. Universidad de Granada. (Documento no publicado).
} 
Abriendo nuevos campos educativos

"La educación en las personas mayores, al igual que la vejez, más que cualquier otra etapa de la vida, debe conducir a construcciones basadas en el paradigma de la experiencia, el diálogo y la trascendencia." ${ }^{63}$ Finalmente salimos al encuentro de un proceso dirigido a la madurez de los años donde al reconocimiento de la ciudadanía, se le concede un valor añadido más allá de la siempre imprecisa frontera de la edad.

Como expresábamos al comienzo del presente trabajo, nuestro objetivo final es definir una nueva concepción de la educación con personas mayores, una educación que logre despertar y estimular nuevas posibilidades de desarrollo personal y social, las cuales vendrán expresadas a distintos ritmos, a distintos gustos y diferentes formas de ser. Este propósito vamos a reconocerlo como campo disciplinar denominado "Educación Expresiva". Su esencia es consolidar un espacio apropiado para los adultos mayores que permita la creación de una cultura que responda a los objetivos lograr sus aspiraciones y materializar el descubrimiento y valoración del capital. Es fundamental recuperar la experiencia, los ideales, los criterios morales, los compromisos profesionales...una sabiduría acumulada por ensayo y error, unidos y fecundados en el campo del quehacer cotidiano. ${ }^{64}$

\section{FUENTES}

Resolución de la Asamblea General de la ONU 217 del 10 de diciembre de 1948.

UNESCO. (1976): Recomendación relativa al desarrollo de la educación de adultos aprobada por la Conferencia General en su decimonovena reunión Nairobi, 26 de noviembre de 1976.

\section{SELECCIÓN BIBLIOGRAFICA}

ALVARADO, E. (1998): Retos del Estado de Bienestar en España a finales de los noventa. Madrid. Tecnos.

BEDMAR, M. y otros. (2004): Gerontagogía. Educación en personas mayores. Granada: Grupo Editorial Universitario.

CONDORCET, J. A. (1945): "Informe sobre la organización general de la Instrucción Pública” en La Escuela Laica. Buenos Aires. Losada

COLECTIVO SITUACIONES. (2004): Algo más sobre la militancia de investigación. Notas al pie sobre procedimientos o (in)decisiones. En VV.AA. Nociones comunes, experiencia y ensayos entre investigación y militancia. Madrid. Traficantes de Sueños.

\footnotetext{
${ }^{63}$ ESCARBAJAL DE HARO, A. (2004): Personas mayores, educación y emancipación: la importancia del trabajo cualitativo. Madrid. Dykinson, p. 260.

${ }_{64}^{64}$ GARCÍA MÍNGUEZ, J. (2004): La educación en personas mayores: ensayo de nuevos caminos. Madrid. Narcea.
}

Rhela. Vol. 12. Año 2009, pp. 129 - 151 
DABOVE, M. I. (2002): Los derechos de los ancianos. Buenos Aires. Ciudad Argentina.

DE BONO, E. (2001): Aprender a crear. Management Digest, 2, 86-89.

DELORS, J. (Coord.) (1996): La educación encierra un tesoro. Informe de la UNESCO de la Comisión Internacional sobre educación para el siglo XXI. Madrid: Santillana.

DÍAZ ALEDO, L. (1993): Envejecer es vivir. Madrid. Popular.

ESCARBAJALDE HARO, A. (1994): La marea gris. En J. Sáez (Coord.), La educación de adultos ¿una nueva profesión? Valencia: Nau Llibres.

(2003): “Personas mayores, educación y aprendizaje. en J. SÁEZ, (Coord.), Educación y aprendizaje en personas mayores. Madrid. Dykinson.

(2004): Personas mayores, educación y emancipación: la importancia del trabajo cualitativo. Madrid. Dykinson.

FAURE, E. y otros. (1972): Aprender a ser. La educación del futuro. Madrid. Alianza.

FÉRNANDEZ LÓPIZ, E. (1998): Psicogerontología. Perspectivas teóricas y cambios en la vejez. Granada. Adhara.

FOUCAULT, M. (1967): Historia de la locura en la época clásica. Madrid. Fondo de Cultura Económica.

FOUCAULT, M. (2003): El yo minimalista y otras conversaciones. Buenos Aires. La Marea.

GARCÍA MÍNGUEZ, J. Y SANCHEZ GARCÍA, A. (1998): Un modelo de educación en los mayores: la interactividad. Madrid. Dykinson.

GARCÍA MÍNGUEZ, J. (1998): "El derecho a aprender sin límite de edad", en J. Sáez y A. Escarbajal (Coords.), La Educación de Personas Adultas. En defensa de la reflexividad crítica. Salamanca. Amarú.

. (1998): "Las personas mayores y el educador social", en J. García Mínguez (Coord.), I Jornadas sobre personas mayores y educadores sociales Granada. Grupo Editorial Universitario.

GARCIA MINGUEZ, J. et Alii. (2003): El refranero, ¿espejo y reflejo de las personas mayores? Madrid. Dykinson. . (Coord.) (2003): De nuevo, la Educación Social. Madrid. Dykinson. . (2004): La educación en personas mayores: ensayo de nuevos caminos. Madrid. Narcea.

.(Coord.) (2005): Programas de Educación Intergeneracional. Acciones Estratégicas. Madrid. Dykinson. 
Abriendo nuevos campos educativos

GOLEMAN, D (2001): La inteligencia encinal. Barcelona. Kairós.

IMSERSO (2002): Las personas mayores en España. Datos estadísticos estatales y por Comunidades Autónomas. Vol. I y II. Madrid. Subdirección General de Planificación, Ordenación y Evaluación. Instituto de Migraciones y Servicios Sociales.

IMSERSO (2004): Las personas mayores en España. Informe 2004. Datos estadísticos estatales y por Comunidades Autónomas. Vol. I y II. Madrid. Subdirección General de Planificación, Ordenación y Evaluación. Instituto de Migraciones y Servicios Sociales.

IMSERSO (2006): Informe 2006. Las personas mayores en España. Datos estadísticos estatales y por Comunidades Autónomas. Vol. Iy II. Madrid. Subdirección General de Planificación, Ordenación y Evaluación. Instituto de Migraciones y Servicios Sociales.

INKELES (1968): ¿Qué es la sociología? Introducción a la ciencia y a la profesión, México. Uthea.

LASPALAS, J. (2003): Introducción a la historiografia de la Educación. Pamplona. EUNSA.

LÓPEZ MARTÍN, R. (2006): Fundamentos politicos de la Educación Social. Madrid. Síntesis.

LORENZO, J. A. (2003): "El marco educativo de la formación universitaria de las personas mayores: necesidad de una política educativa", en J. A. Lorenzo (Dir.), Políticas sociales, educativas y financiación de la Formación Universitaria de Personas Mayores y su proyección social (pp.125-138). Madrid. IMSERSO.

MAÑÓS. Q. (1998): Animación Estimulativa para personas mayores discapacitadas. Madrid. Narcea.

MARÍAS, J. (1993): La educación sentimental. Madrid. Alianza.

(2004): Anatomía del miedo: un tratado sobre la valentía. Barcelona. Anagrama.

MARTÍN GARCÍA, A. V. (1994): Educación y envejecimiento. Barcelona. PPU.

MONTERO GARCÍA, I. (2005): El interés de las personas mayores por la educación: qué educación. Estudio de campo. Tesis Doctoral. Universidad de Granada. (Documento no publicado).

MONTERO GARCÍA, I. (2007): Proyecto Docente. Pedagogía Social. Departamento de Pedagogía. Facultad de Ciencias de la Educación. Universidad de Granada. (Documento no publicado). 
MUÑOZ GALIANO, I. (2003): "Una apuesta para el futuro: la educación en personas mayores", en J. A. Lorenzo Vicente (Dir.), Políticas sociales, educativas y financiación de la formación universitaria de personas mayores y su proyección social. Madrid: IMSERSO.

MUÑOZ GALIANO, I. (2005): Estereotipos sobre la vejez: un problema en vías de superación. Revista Pedagogía y Saberes No 22.

MUÑOZ GALIANO, I. (2006): Estilos educativos en personas mayores, en F. Añaños Bedriñana (Coord.). Educación Social: formación realidad y retos (247-255). Granada. Grupo Editorial Universitario.

NÚÑEZ, V. (1999): Pedagogía Social: cartas para navegar en el nuevo milenio. Buenos Aires. Santillana.

NÚÑEZ, V. (2002): La educación en tiempos de incertidumbre: la apuesta de la Pedagogía Social. Barcelona. Gedisa.

ORDUNA, G. y Naval, C. (Edits) (2001): Gerontología educativa. Barcelona. Ariel.

ORTEGA, Esteban, J. (2003): Realidades y desafíos. Cuadernos de Pedagogía.

PÉREZ SERRANO, G. (2003): Pedagogía Social. Educación Social. Madrid. Nancea.

PÉREZ SERRANO, G. (2004a): Calidad de vida en personas mayores. Madrid. Dykinson.

PÉREZ LEDESMA. M(2001). “Ese artículo de lujo seriamente odioso”, en Archipiélago.

PLANELLA, J. (2006): Los hijos de Zotikos: una antropología de la Educación Social. Valencia. Nau Llibres.

PETRUS, T (1998): Pedagogía Social, Barcelona. Ariel.

QUINTANA CABANAS, J. M. (1999): Textos clásicos de Pedagogía Social. Valencia. Nau Llibres.

RECIO FIGUEIRAS, E. M. (1986): La planificación de los recursos humanos en la empresa. Barcelona. Hispano Europa.

SÁEZ CARRERAS, J. (Coord.) (2002): Pedagogía Social y Programas Intergeneracionales. Educación de personas mayores. Málaga. Aljibe.

. (2004): La profesionalización de los educadores sociales: en busca de la competencia educativa cualificadora. Madrid. Dykinson.

. (2005): "La socialización de las profesiones. La construcción de la identidad profesional del educador social”, en C. Mínguez (Coord.), La Educación Social: discurso, práctica y profesión. Madrid. Dykinson. 
Abriendo nuevos campos educativos

. (2007): Pedagogía Social. Historia, profesión y competencias. Madrid. Pearson.

SÁEZ, J. Y GARCÍA MOLINA, J. (2006): Pedagogía Social. Pensar la Educación Social como profesión. Madrid. Alianza Editorial.

UCAR, J (2006): "El por qué y para qué de la Pedagogía Social ", en Planella La Pedagogía Social en la sociedad de la información. Barcelona. UOC.

VYGOTSKII, (1989): El desarrollo de los procesos psicológicos superiores. Barcelona. Crítica.

VILANAOU, C. (2002): Jordi Monés i el Seminari d'Historia de 1'Ensengament: quam la historia de la pedagogía esclava historia de l'educatio social. Educari i Historia, 5, 13-59.

VIÑAO A. y De Gabriel, N. (Eds.) (1997): La investigación histórico-educativa: tendencias actuales. Barcelona. Paidós.

VIÑAO, A. Y MORENO, P. C. (2003): La periferia del sistema educativo. Cuadernos de Pedagogía, 26, 29-38.

WITHNAL, A (2003): Tres décadas de Gerontología Educativa: logros y retos. En J Sáez, Educación y aprendizaje en las personas mayores, Madrid. Dykinson.

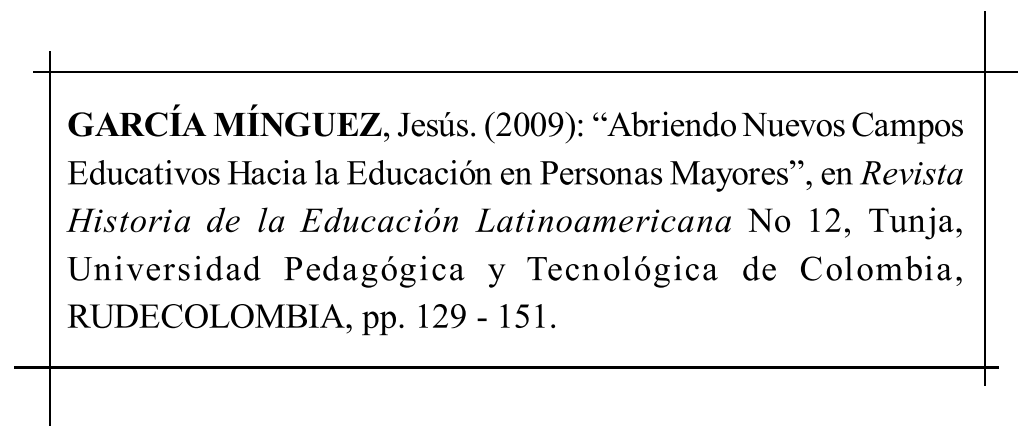

Rhela. Vol. 12. Año 2009, pp. 129 - 151 